\title{
Glucose management for exercise using continuous glucose monitoring: should sex and prandial state be additional considerations? Reply to Yardley JE and Sigal RJ [letter]
}

\author{
Othmar Moser ${ }^{1,2}$ (1) $\cdot$ Michael C. Riddell ${ }^{3}$ (D) - Max L. Eckstein ${ }^{1,2}$ (1) Peter Adolfsson ${ }^{4,5}$ (1) Rémi Rabasa-Lhoret ${ }^{6,7,8,9}$ (D) \\ Louisa van den Boom ${ }^{10}$ (D) $\cdot$ Pieter Gillard ${ }^{11}$ (D) $\cdot$ Kirsten Nørgaard ${ }^{12}$ (D) $\cdot$ Nick S. Oliver $^{13}$ (D) $\cdot$ Dessi P. Zaharieva ${ }^{14}$ (D) \\ Tadej Battelino ${ }^{15,16}$ (D) Carine de Beaufort ${ }^{17,18}$ (I) Richard M. Bergenstal ${ }^{19}$ (D) $\cdot$ Bruce Buckingham ${ }^{14}$ (iD $\cdot$ \\ Eda Cengiz ${ }^{20,21}$ (D) - Asma Deeb ${ }^{22}$ (D) - Tim Heise ${ }^{23}$ (D) - Simon Heller ${ }^{24,25}$ (D) Aaron J. Kowalski ${ }^{26}$ (D) \\ Lalantha Leelarathna ${ }^{27,28}$ (D) - Chantal Mathieu ${ }^{11}$ (D) $\cdot$ Christoph Stettler ${ }^{29}$ (D) $\cdot$ Martin Tauschmann ${ }^{30}$ (D) \\ Hood Thabit $^{27}$ (D) Emma G. Wilmot ${ }^{31,32}$ (D) Harald Sourij $^{2}$ (D) Carmel E. Smart $^{33,34}$ (D) Peter G. Jacobs ${ }^{35}$ (D) \\ Richard M. Bracken ${ }^{36}$ (D) Julia K. Mader ${ }^{2}$ (D)
}

Received: 23 November 2020 / Accepted: 25 November 2020 / Published online: 4 February 2021

(C) The Author(s) 2021

Keywords Carbohydrates · CGM · Exercise $\cdot$ Physical activity · Type 1 diabetes

\section{Abbreviations \\ CGM Continuous glucose monitoring \\ HIIE High-intensity interval exercise}

To the Editor: We thank Dr Yardley and Dr Sigal for their comments on the position statement pertaining to the use of continuous glucose monitoring (CGM) systems around exercise in type 1 diabetes $[1,2]$. The letter by Yardley and Sigal was centred on four points: (1) the potential difference in risk of hypoglycaemia in active vs inactive people; (2) possible sex differences in exercise-related hypoglycaemia risk; (3) the role of bolus insulin administration to prevent and/or correct exerciserelated hyperglycaemia that is sometimes associated with highintensity interval exercise (HIIE) and/or resistance exercise; and (4) the role of the prandial state on glucose responses during exercise.

As Yardley and Sigal state [1], the role of fitness level and/or exercise experience on the risk for hypoglycaemia during or after exercise is unclear. To clarify, our position statement did not mention that 'inactive' people with type 1 diabetes have a higher risk of hypoglycaemia per se; however, it was discussed that 'individuals who do not routinely exercise may face an increased

Othmar Moser

othmar.moser@uni-bayreuth.de

Extended author information available on the last page of the article risk of hypoglycaemia', 'partially' in line with the study of Bohn et al $[2,3]$. Yardley and Sigal reference the article by Al Khalifah et al [4] as evidence that people who are more aerobically fit may have a higher likelihood of becoming hypoglycaemic during exercise compared with those less fit. A closer look at the data from this paper, however, indicates that there was a much larger number of participants in the 'good fitness' group who performed treadmill exercise $(n=19)$ compared with exercise on the stationary bike $(n=4)$, whereas, in the 'poor fitness' group, a larger number of participants performed exercise on the stationary bike $(n=11)$ compared with the treadmill $(n=$ 9). A larger percentage of hypoglycaemia occurred across both groups with the treadmill exercise compared with exercise on the stationary bike, perhaps partly because the treadmill exercise was twice as long as that on the stationary bike. For this reason, a number of confounders prevent a conclusion on the impact of fitness level on likelihood of hypoglycaemia based on these results. Based on the large cross-sectional study by Bohn et al [3] and in agreement with the present writing groups' clinical experience, we would still recommend higher glucose levels during exercise for those that are not routinely exercising to ensure safe exercise and a low risk of hypoglycaemia. Importantly, if a person exercises routinely and/or has a low risk of hypoglycaemia over a period of 3 months, then the glycaemic thresholds for carbohydrate consumption might be adjusted, as emphasised in our statement [2].

Thank you for discussing several studies showing how hypoglycaemia risk during exercise can be different for male individuals vs female individuals. In Fig. 1 of the manuscript 
by Bohn et al, severe hypoglycaemia was demonstrated to occur more often in physically active female participants compared with male participants; however, the difference was small (two events per 100 person-years) [3]. Brockman et al [5] showed that it was male individuals, not females, who experienced the sharper decrease in glucose during resistance exercise and also higher rates of hypoglycaemia. Given the conflicting results, small differences between the groups and the limited studies in this area, we provided an initial focus on the overall population of people with type 1 diabetes, separating them into adults, adolescents and children, with subgroups based on risk of hypoglycaemia [2]. While we anticipate that future studies will provide a more complete picture on the role of sex in modulating exercise-induced changes in blood glucose levels, our position statement [2] is a first step towards evidence-based general recommendations about how to use CGM systems around exercise.

The authors mention in their letter that we recommend a bolus insulin correction in advance of HIIE and resistance exercise. While dosing insulin in advance of HIIE and resistance exercise may be dangerous in some situations, for the points raised in our position statement [2], we recommended a $50 \%$ reduced correction factor of the regular insulin dose at glucose levels $>10 \mathrm{mmol} / \mathrm{l}$, and not an insulin correction dose before HIIE and resistance exercise in general (see Table 1 in the position statement [2]). We also note that pre-exercise extreme hyperglycaemia (sensor glucose levels $>15 \mathrm{mmol} / \mathrm{l}$ ) can be treated with an insulin bolus (50\% of a typical correction dose) [2]. We maintain this recommendation, given the strong emphasis for the use of CGM in this position statement to allow for the safe monitoring of glucose levels post insulin correction [2]. We feel that it is unwarranted to recommend that people with type 1 diabetes ignore their pre-exercise hyperglycaemia prior to exercise or competition [6].

We agree with Yardley and Sigal that a determining factor of whether glucose increases during resistance exercise or HIIE may be dependent on the prandial state [1]. We agree that we may expect to see elevated glucose levels during resistance exercise and HIIE when done in the fasted state and addressed this point in the position statement, where we stated that 'if sensor glucose is expected to increase, as often seen in people performing fasted high-intensity interval training, resistance training and, also, in training above the anaerobic threshold, then an insulin correction can be administered at the onset of, as well as during exercise (50\% of typical correction factor)' [2].

The four points discussed here highlight the multiple factors involved in intra- and interindividual glucose response to physical activity and exercise in individuals living with type 1 diabetes and, accordingly, the difficulties encountered by them in anticipating and managing glucose in these situations. Thus, we would like to thank the authors for their support on this position statement and appreciate the additional viewpoints that will be considered in future updates of a rapidly advancing area.

Funding Open Access funding enabled and organized by Projekt DEAL.

Authors' relationships and activities $\mathrm{OM}$ has received lecture fees from Medtronic, travel grants from Novo Nordisk A/S, Novo Nordisk AT, Novo Nordisk UK and Medtronic AT, research grants from Sêr Cymru II COFUND fellowship/European Union, Sanofi-Aventis, Novo Nordisk A/S, Novo Nordisk AT, Dexcom Inc., as well as material funding from Abbott Diabetes Care. MCR has received speaker's honorarium from Medtronic and Insulet and has served on advisory boards for Dexcom, Sanofi and Eli Lilly. MLE has received a KESS2/European Social Fund scholarship and travel grants from Novo Nordisk A/S and SanofiAventis. PA has received research support or advisory board fees from Eli Lilly, Novo Nordisk and Roche, funding from Research and Development, Region Halland, and is an employee of Region Halland. RRL reports having received a consumable gift (in kind) from Medtronic. $\mathrm{KN}$ is a shareholder of Novo Nordisk, has received research support from Novo Nordisk, Roche Diagnostics and Zealand Pharma, has received lecture fees from Medtronic, Roche Diagnostics, Rubin Medical, Sanofi, Zealand Pharma, Novo Nordisk and Bayer, and has served on advisory panels for Medtronic, Abbott and Novo Nordisk. NSO has received honoraria for speaking and advisory board participation from Abbott Diabetes, Dexcom, Medtronic Diabetes and Roche Diabetes. DPZ has received speaker's honoraria from Medtronic Diabetes, Ascensia Diabetes and Insulet Corporation. TB has received honoraria for participation on advisory boards for Novo Nordisk, Sanofi, Eli Lilly, Boehringer, Medtronic and Bayer HealthCare, and as a speaker for AstraZeneca, Eli Lilly, Bayer, Novo Nordisk, Medtronic, Sanofi and Roche, and owns stocks of DreaMed Diabetes. CDB has received speaker honoraria from MiniMed Medtronic and is a member of its European Psychology Advisory Board. RMBe has received research support from, consulted for or has been on a scientific advisory board for Abbott Diabetes Care, Dexcom, Eli Lilly, Johnson \& Johnson, Medtronic, Novo Nordisk, Onduo, Roche, Sanofi and United HealthCare. BB received grant support and advisory board fees from Medtronic Diabetes and ConvaTec, grant support and presentation fees from Insulet, advisory board fees from Novo Nordisk and Profusa, grant support from Eli Lilly, grant support and equipment from Dexcom, and is holding patent 61197230 on a hypoglycaemia prediction algorithm. EC is a scientific advisory board member/consultant for Novo Nordisk, Adocia, MannKind, Lexicon and Arecor, and a speaker for Novo Nordisk. TH is a shareholder of Profil, which has received research funds from Adocia, Boehringer Ingelheim, Dance Pharmaceuticals, Eli Lilly, Johnson \& Johnson, MedImmune, Merck Sharp and Dohme, Mylan, Nordic Bioscience, Novo Nordisk, Poxel, Roche Diagnostics, Saniona, Sanofi, Senseonics and Zealand Pharma. SH has served as a consultant or speaker for Lilly, Novo Nordisk, Takeda, Boehringer Ingelheim, Mannkind, Sanofi-Aventis, Zealand Pharma and UN-EEG. LL reports having received speaker honoraria from Animas, Abbott, Insulet, Medtronic, Novo Nordisk, Roche and Sanofi, serving on advisory panels for Animas, Abbott, Novo Nordisk, Dexcom, Medtronic, Sanofi, and Roche, and research support from Novo Nordisk and Dexcom. CM serves or has served on the advisory panel for Novo Nordisk, Sanofi, Merck Sharp and Dohme, Eli Lilly and Company, Novartis, AstraZeneca, Boehringer Ingelheim, Hanmi Pharmaceuticals, Roche, Medtronic, ActoBio Therapeutics, Pfizer, Dianax and UCB. CS reports having received speaker honoraria from Medtronic and Ypsomed, and serving on advisory panels for Novo Nordisk, Medtronic, Roche and Sanofi. MT has received speaker honoraria from MiniMed Medtronic and Novo Nordisk. EGW has received personal fees from Abbott 
Diabetes Care, Dexcom, Eli Lilly, Medtronic, Novo Nordisk and SanofiAventis. HS has received honoraria, travel support or unrestricted research grants by Amgen, Astra Zeneca, Boehringer Ingelheim, Eli Lilly, MSD, Novo Nordisk and Sanofi-Aventis. PGJ has a financial interest in Pacific Diabetes Technologies Inc., a company that may have a commercial interest in the results of this research and technology. $\mathrm{RMBr}$ has received honoraria as well as travel and educational grant support from Boehringer Ingelheim, Eli Lilly and Company, Novo Nordisk and Sanofi-Aventis. JKM is a member of the advisory board of Boehringer Ingelheim, Eli Lilly, Medtronic, Prediktor A/S, Roche Diabetes Care and Sanofi, and received speaker honoraria from Abbott Diabetes Care, AstraZeneca, Dexcom, Eli Lilly, Medtronic, Merk Sharp \& Dohme, Novo Nordisk A/S, Roche Diabetes Care, Sanofi, Servier and Takeda. The remaining authors have no relevant conflicts of interest to disclose.

Contribution statement All authors were responsible for drafting the article and revising it critically for important intellectual content. All authors approved the version to be published.

Open Access This article is licensed under a Creative Commons Attribution 4.0 International License, which permits use, sharing, adaptation, distribution and reproduction in any medium or format, as long as you give appropriate credit to the original author(s) and the source, provide a link to the Creative Commons licence, and indicate if changes were made. The images or other third party material in this article are included in the article's Creative Commons licence, unless indicated otherwise in a credit line to the material. If material is not included in the article's Creative Commons licence and your intended use is not permitted by statutory regulation or exceeds the permitted use, you will need to obtain permission directly from the copyright holder. To view a copy of this licence, visit http://creativecommons.org/licenses/by/4.0/.

\section{References}

1. Yardley J, Sigal R (2020) Glucose management for exercise using continuous glucose monitoring: should sex and prandial state be additional considerations? Diabetolgia. https://doi.org/10.1007/ s00125-020-05373-4

2. Moser O, Riddell MC, Eckstein ML et al (2020) Glucose management for exercise using continuous glucose monitoring (CGM) and intermittently scanned CGM (isCGM) systems in type 1 diabetes: position statement of the European Association for the Study of Diabetes (EASD) and of the International Society for Pediatric and Adolescent Diabetes (ISPAD) endorsed by JDRF and supported by the American Diabetes Association (ADA). Diabetologia 63:25012520. https://doi.org/10.1007/s00125-020-05263-9

3. Bohn B, Herbst A, Pfeifer M et al (2015) Impact of physical activity on glycemic control and prevalence of cardiovascular risk factors in adults with type 1 diabetes: a cross-sectional multicenter study of 18 , 028 patients. Diabetes Care 38(8):1536-1543. https://doi.org/10. 2337/dc15-0030

4. Al Khalifah RA, Suppère C, Haidar A, Rabasa-Lhoret R, Ladouceur M, Legault L (2016) Association of aerobic fitness level with exercise-induced hypoglycaemia in Type 1 diabetes. Diabet Med 33(12):1686-1690. https://doi.org/10.1111/dme.13070

5. Brockman NK, Sigal RJ, Kenny GP, Riddell MC, Perkins BA, Yardley JE (2020) Sex-related differences in blood glucose responses to resistance exercise in adults with type 1 diabetes: a secondary data analysis. Can J Diabetes 44(3):267-273. https://doi. org/10.1016/j.jcjd.2019.08.006

6. Riddell MC, Scott SN, Fournier PA et al (2020) The competitive athlete with type 1 diabetes. Diabetologia 63(8):1475-1490. https:// doi.org/10.1007/s00125-020-05183-8

Publisher's note Springer Nature remains neutral with regard to jurisdictional claims in published maps and institutional affiliations.

\section{Affiliations}

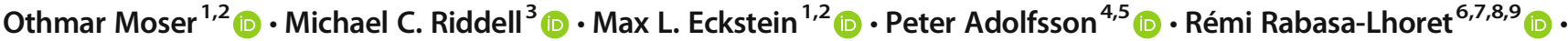 Louisa van den Boom ${ }^{10}$ (D) - Pieter Gillard ${ }^{11}$ (D) Kirsten Nørgaard ${ }^{12}$ (D) . Nick S. Oliver ${ }^{13}$ (D) - Dessi P. Zaharieva ${ }^{14}$ (D) Tadej Battelino ${ }^{15,16}$ (D) . Carine de Beaufort ${ }^{17,18}$ (D) Richard M. Bergenstal $^{19}$ (D) $\cdot$ Bruce Buckingham $^{14}$ (D) Eda Cengiz ${ }^{20,21}$ (D) $\cdot$ Asma Deeb $^{22}$ (D) - Tim Heise ${ }^{23}$ (D) $\cdot$ Simon Heller ${ }^{24,25}$ (D) - Aaron J. Kowalski ${ }^{26}$ (D) Lalantha Leelarathna ${ }^{27,28}$ (D) $\cdot$ Chantal Mathieu ${ }^{11}$ (D) $\cdot$ Christoph Stettler $^{29}$ (D) $\cdot$ Martin Tauschmann $^{30}$ (D) $\cdot$ Hood Thabit $^{27}$ (D) - Emma G. Wilmot ${ }^{31,32}$ (D) Harald Sourij $^{2}$ (ID - Carmel E. Smart ${ }^{33,34}$ (D) Peter G. Jacobs ${ }^{35}$ (D) Richard M. Bracken ${ }^{36}$ (D) Julia K. Mader ${ }^{2}$ (D)}

1 Division of Exercise Physiology and Metabolism, Department of Sport Science, University of Bayreuth, Bayreuth, Germany

2 Division of Endocrinology and Diabetology, Department of Internal Medicine, Medical University of Graz, Graz, Austria

3 School of Kinesiology and Health Science, York University, Toronto, ON, Canada

4 Department of Pediatrics, The Hospital of Halland, Kungsbacka, Sweden

5 Sahlgrenska Academy at University of Gothenburg, Institution of Clinical Sciences, Gothenburg, Sweden

6 Institut de Recherches Cliniques de Montréal, Montréal, QC, Canada
7 Endocrinology Division Centre Hospitalier Universitaire de Montréal, Montréal, QC, Canada

8 Nutrition Department, Faculty of Medicine, Université de Montréal, Montréal, QC, Canada

9 Montreal Diabetes Research Centre, Montréal, QC, Canada

10 Division of Pediatric Diabetology, DRK Children's Hospital, Siegen, Germany

11 Department of Endocrinology, University Hospitals Leuven, KU Leuven, Leuven, Belgium

12 Steno Diabetes Center Copenhagen, University of Copenhagen, Copenhagen, Denmark 
13 Department of Metabolism, Digestion and Reproduction, Faculty of Medicine, Imperial College, London, London, UK

14 Department of Pediatric Endocrinology and Diabetes, Stanford University School of Medicine, Stanford, CA, USA

15 Department of Paediatric Endocrinology, Diabetes and Metabolic Diseases, UMC - University Children's Hospital, University Medical Centre Ljubljana, Ljubljana, Slovenia

16 Faculty of Medicine, University of Ljubljana, Ljubljana, Slovenia

17 Department of Pediatric Diabetes and Endocrinology, Centre Hospitalier Luxembourg, Luxembourg, Luxembourg

18 Department of Pediatrics, Free University Brussels (VUB), Brussels, Belgium

19 International Diabetes Center, Minneapolis, MN, USA

20 Department of Pediatrics, Yale School of Medicine, New Haven, CT, USA

21 Bahçeșehir Üniversitesi, Istanbul, Turkey

22 Paediatric Endocrinology Division, Shaikh Shakhbout Medical City, Abu Dhabi, United Arab Emirates

23 Profil, Neuss, Germany

24 Department of Oncology \& Metabolism, The Medical School, University of Sheffield, Sheffield, UK

25 Sheffield Teaching Hospitals NHS Foundation Trust, Sheffield, UK

26
27 Manchester Diabetes Centre, Manchester University NHS Foundation Trust, Manchester Academic Health Science Centre, Manchester, UK

28 Department of Diabetes, Endocrinology and Gastroenterology, Faculty of Biology, Medicine and Health, University of Manchester, Manchester, UK

29 Department of Diabetes, Endocrinology, Nutritional Medicine and Metabolism, Inselspital, Bern University Hospital and University of Bern, Bern, Switzerland

Department of Pediatrics and Adolescent Medicine, Medical University of Vienna, Vienna, Austria

31 Diabetes Department, Royal Derby Hospital, University Hospitals of Derby and Burton NHSFT, Derby, UK

32 Faculty of Medicine \& Health Sciences, University of Nottingham, Nottingham, UK

33 School of Health Sciences, University of Newcastle, Callaghan, NSW, Australia

34 Department of Paediatric Diabetes and Endocrinology, John Hunter Children's Hospital, Newcastle, NSW, Australia

35 Department of Biomedical Engineering, Oregon Health \& Science University, Portland, OR, USA

36 Applied Sport, Technology, Exercise and Medicine Research Centre (A-STEM), College of Engineering, Swansea University, Swansea, UK 